\title{
Application of Bonded Joints for Quantitative Analysis of Adhesion
}

\author{
Jarmila Trpčevská, ${ }^{1}$ Mária Kollárová, ${ }^{2}$ Eva Zdravecká, ${ }^{3}$ and Jana Tkáčová ${ }^{3}$ \\ ${ }^{1}$ Faculty of Metallurgy, Technical University of Košice, 04001 Košice, Slovakia \\ ${ }^{2}$ U.S. Steel Košice, s.r.o., 04454 Košice, Slovakia \\ ${ }^{3}$ Faculty of Mechanical Engineering, Technical University of Košice, 04001 Košice, Slovakia
}

Correspondence should be addressed to Eva Zdravecká; eva.zdravecka@tuke.sk

Received 18 November 2015; Accepted 16 February 2016

Academic Editor: Achim Trampert

Copyright (C) 2016 Jarmila Trpčevská et al. This is an open access article distributed under the Creative Commons Attribution License, which permits unrestricted use, distribution, and reproduction in any medium, provided the original work is properly cited.

\begin{abstract}
The performance of hot-dip coated steel sheets is associated with properties of the zinc coatings on steel substrate. For the characterization of the adhesion behaviour of zinc coating on steel various tests were employed. The study was focused on quantification assessment of galvanized coating adhesion to substrates. Methods for evaluation of the bonding strength of zinc coating by the shear strength and the T-peel tests applying four special types of adhesives were used. The experimental tests of bonded joints show that the adhesion of the zinc coating to the substrate was higher than that of the applied adhesive with the highest strength.
\end{abstract}

\section{Introduction}

Zinc coated steel sheets are very demanding in many industrial branches. According to their further processing and utilization the wide assortment is produced with different combination of special properties, for example, in automobile industry, besides the excellent corrosive resistance, and also high deformability, weldability, paintability, and stability of mechanical properties are required.

Zinc coatings produced by hot-dip galvanizing are a multicomponent system consisting of several phases. Intermetallic phases may impair the formability due to their brittleness and powdering; the alloyed coating can fracture during stamping process, resulting in the exfoliation of the coating. The stamping of hot-dip coated steel sheets is frequently associated with problems such as galling and scratching. Zinc coated steel sheet applied in automotive body panels has to meet very strict coating adhesion requirements to prevent coating delamination during deformation [1-3].

The understanding of the relationship between the coating/steel interface chemistry and microstructure on the one hand and coating adhesion on the other remains in the centre of research interest. Adhesion as a multidisciplinary topic includes surface chemistry, physics, rheology, polymer chemistry, and mechanics of materials (i.e., stress analysis), polymer physics, fracture analysis, and other subjects. Describing the mechanism of adhesion in simple terms is difficult due to the complexity and evolving understanding of the subject [3-6].

The adhesion of coatings can be analysed by various methods. Based on the studies of the effect of alloying elements on coating behavior and experimental work focused with the development of galvanized steels, various alloying elements are being introduced into the zinc coatings as well as the steel substrate to form various coating systems for different applications. Their structure and composition of the interfacial layer have been investigated using a variety of analytical methods, such as scanning electron microscopy (SEM), energy-dispersive spectroscopy, X-ray diffraction (XRD), and transmission electron microscopy as reported. For the characterization of the adhesion performance of the various zinc coatings on steel more conventional tests are employed, for example, U-bend, V-bend, and four-point bend tests, impact test, single lap shear test, draw bead, cylindricalcup test, and scratch test. However, these methods provide especially qualitative results. A quantitative evaluation is very complicated. The results of the single lap shear tensile test rely on the strength and adhesion of the adhesive, which must 
TABLE 1: Chemical and mechanical properties of substrate material.

\begin{tabular}{|c|c|c|c|c|c|c|c|}
\hline Material & $\mathrm{C}_{\max }(\%)$ & Mn (\%) & $\mathrm{Si}_{\max }(\%)$ & $\mathrm{P}_{\max }(\%)$ & $\mathrm{S}_{\max }(\%)$ & $\mathrm{Al}(\%)$ & $\mathrm{N}_{\max }(\%)$ \\
\hline DX53D-Z & 0.03 & $0.12-0.19$ & 0.01 & 0.015 & 0.012 & $0.04-0.065$ & 0.006 \\
\hline \multicolumn{2}{|c|}{ Yield strength $R_{e \max }(\mathrm{MPa})$} & \multicolumn{3}{|c|}{ Tensile strength $R_{m \text { max }}(\mathrm{MPa})$} & \multicolumn{3}{|c|}{ Ductility $A_{80 \min }(\%)$} \\
\hline \multicolumn{2}{|c|}{260} & \multicolumn{3}{|c|}{380} & \multicolumn{3}{|c|}{30} \\
\hline
\end{tabular}

be superior to that of the zinc coatings. A test method for the quantitative evaluation of the adhesive strength of zinc coatings is still lacking but is greatly required $[3,5,7-9]$.

The contribution is oriented to a quantitative assessment of the zinc coating adhesion to the substrate with bonding tests (shear strength and the T-peel tests) applying special types of adhesives.

\section{Experiments}

The adhesion of the zinc coating was studied on hot-dip zinc coated low carbon steel sheet DX53D $+Z$ of deep drawing quality for cold forming according to EN 10327:2004.

Chemical and mechanical properties of substrate material are shown in Table 1.

From the area of industrial adhesives we focused on advanced strength adhesives designed to meet the demanding requirements of the industry as follows.

Adhesive A (LETOXIT KFL 120). Adhesive A is one component epoxy adhesive with hardening system, in the form of dark gray film $0.025-0.3 \mathrm{~mm}$ thick, flexible, and plastic at room or elevated temperatures. Curing is performed at the temperature of $120^{\circ} \mathrm{C}-125^{\circ} \mathrm{C}$ for one hour; in the process of curing the bonded joint is fixed by applying a pressure of 0.05-0.1 MPa. Bonded joints exhibit very good mechanical properties when loaded under temperatures ranging from $75^{\circ} \mathrm{C}$ to $+100^{\circ} \mathrm{C}$ with shear strength at tensile loading 36$41 \mathrm{MPa}$ and peel strength $4-7 \mathrm{~N} / \mathrm{mm}$ at $20^{\circ} \mathrm{C}$. Therefore the adhesive is particularly useful for bonding aircraft structures, land means of transport (both road and rail), and other demanding applications.

Adhesive B (LETOXIT PL 20). Adhesive B is two-component structural paste adhesive, cured at normal or elevated temperature with shear strength at tensile loading $31-36 \mathrm{MPa}$ and peel strength $4-7 \mathrm{~N} / \mathrm{mm}$ at $20^{\circ} \mathrm{C}$. The joint achieves high shear strength and good peel strength at temperatures up to $80^{\circ} \mathrm{C}$. The complete strength is obtained by heating at temperature of $120^{\circ} \mathrm{C}$ for one hour.

Adhesive C (RK 1500). Adhesive C is two-component system based on methacrylate, which cure at room temperature with shear strength at tensile loading $25 \mathrm{MPa}$ at $20^{\circ} \mathrm{C}$. Polymerization starts as soon as the adhesive- and activator-wetted components are joined together. This adhesive is stable at temperature range from $-50^{\circ} \mathrm{C}$ up to $135^{\circ} \mathrm{C}$.

Adhesive D (EPIDIAN-5). Adhesive D is a two-part system consisting of an epoxy resin and a hardener. Full cure and strength is obtained in 24 hours.

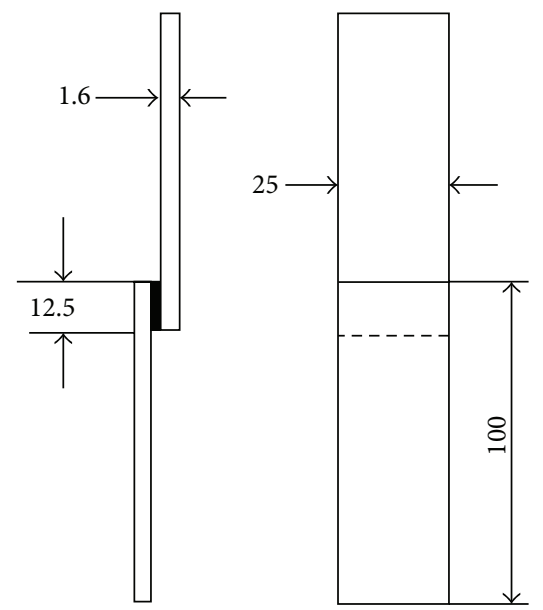

FIgURE 1: Test specimens for lap shear test.

The surface preparation is basic requirement for a good bond. A clean surface is a necessary condition for adhesion but it is not a sufficient condition for bond durability. Most structural adhesives work as a result of the formation of chemical bonds (mainly covalent, but some ionic and static attractive bonds may also be present) between the adherend surface atoms and the compounds constituting the adhesive [10-12].

The surface preparation before bonding usually is recommended by different methods, such as degreasing and roughening and sand blasting. Mechanical treatment as well as oxidation of metals is sometimes viewed as a modification of pretreatment. Degreasing was realized in two steps: (a) samples were immersed in alkaline solution Radalod $^{\mathrm{TM}}$ (Pragochema) and then were washed with water; (b) samples were degreased in pure acetone in ultrasonic cleaner repeatedly four times. The joint with the adhesive was placed in aluminium jig made to exact specifications so that adhesive thickness was maintained. Curing was carried out in numerically controlled autoclave in vacuum at temperature according to type of adhesive with elimination of bubbles and other inhomogeneities formation which can degrade the strength of adhesive joints.

The adhesive lap joint shear strength test is used especially for comparing and selecting adhesives or bonding processes.

Sample for lap shear test according to ASTM D1002 Adhesive Lap Joint Shear Testing [13] is shown in Figure 1. Specimens with adhesive joints were tested in tension by the Instron 8501 test machine with a $50 \mathrm{kN}$ load cell. Loading 


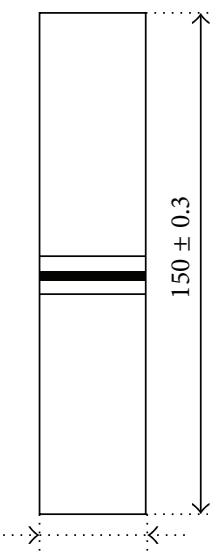

$30-0.3$

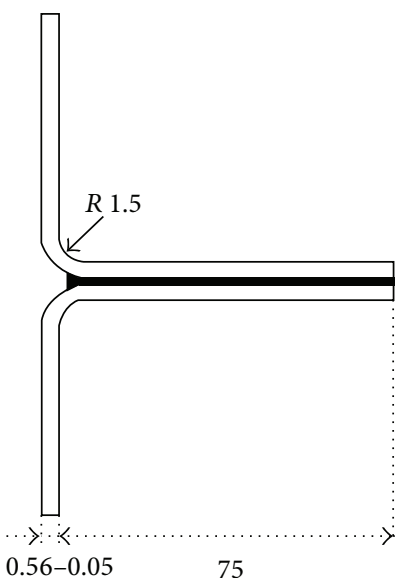

$0.56-0.05 \quad 75$
FIGURE 2: Test specimens for T-peel strength.

rate was $1.5 \mathrm{~mm} \cdot \mathrm{min}^{-1}$. The shear strength $\tau$ was calculated as follows:

$$
\tau=\frac{F}{S}
$$

where $\tau$ is the shear strength ( $\mathrm{MPa}), F$ is the maximum force applied $(\mathrm{N})$, and $S$ is the area of bonded joint $\left(\mathrm{mm}^{2}\right)$.

Average shear strength was calculated as arithmetic mean of shear strengths of ten tested samples for each type of adhesive.

Sample for measuring T-peel strength according to EN ISO 11339:2010 [14] is shown in Figure 2. Loading speed was $45 \mathrm{~mm} / \mathrm{min}$.

The primary purpose of the T-peel test is to determine the relative peel resistance of adhesive bonds between flexible adherends by means of a T-type specimen. Tested joint is subjected to static tension, the bonded portion of the specimen remains perpendicular to the applied load, and gradual separation (peeling) of bonded areas occurs. To define the peel strength the average peeling load per unit width is used. This is taken from the force-displacement curve after the initial peak reading.

The average peel strength $\sigma_{P S}$ was calculated as follows:

$$
\sigma_{P S}=\frac{F_{S}}{b}
$$

where $F_{S}$ is average force $(\mathrm{N})$ given by average height calculated from planimetric area of diagram in the range 30 up to $90 \%$ of length of total diagram and $b$ is width of bonded joint (mm).

For each adhesive and each type of test 10 samples were prepared.

Bonded joints for T-peel test represent a critical load case and therefore samples fabricated of steel sheets with dimensions of $300 \times 1500 \mathrm{~mm}$ were tested in-service.

\section{Results and Discussion}

Although an extensive range of adhesive test methods is available as national and international standards, most of

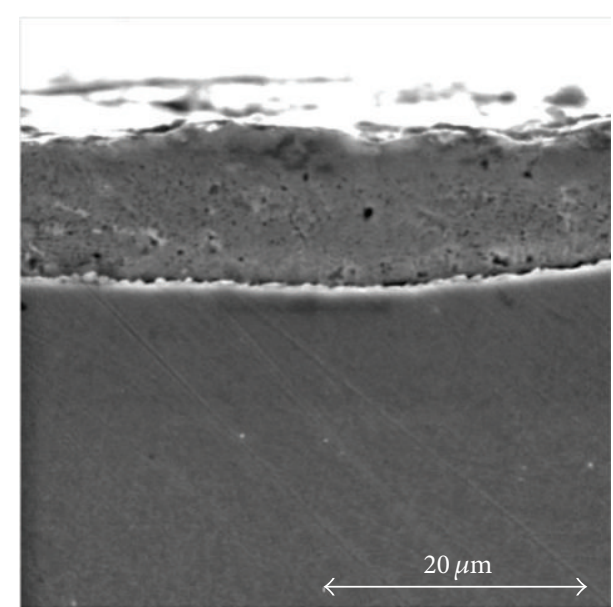

FIgURE 3: SEM image of cross section of the zinc coating on steel substrate.

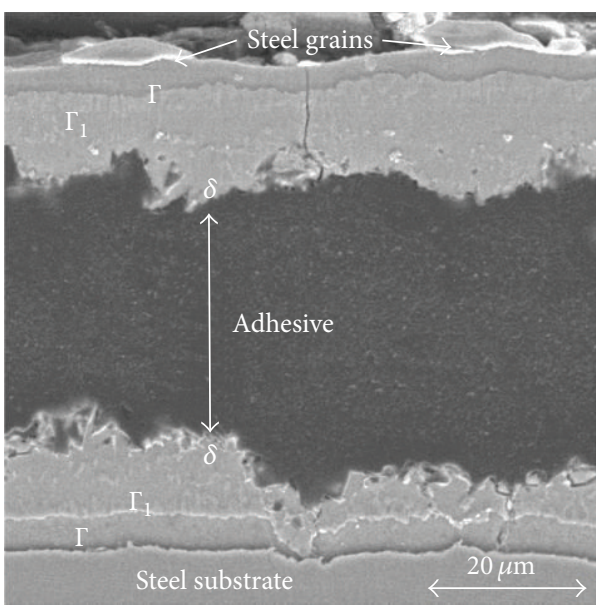

FIGURE 4: SEM image of cross section of bonded joint.

these tests can only be used for qualitative measurements, providing a means of checking the effectiveness of different surface preparations and comparing mechanical properties of different adhesive systems (i.e., ranking adhesive formulations). A limited number of test methods are suitable for generating engineering data, particularly for determining structural integrity of adhesively bonded structures subjected to static, cyclic, and environmental effects.

Cross section of the zinc coating on steel substrate before bonding is shown in Figure 3. The roughness was investigated using by HOMMEL tester; mean value $\mathrm{Ra}=1.78 \mu \mathrm{m}$ was recorded.

Figure 4 is a SEM image of cross section of the zinc coating on the DX53-steel substrate after bonding with phase structure in the order of $\Gamma$ (Fe3Zn10, bcc, brittle, hard), $\Gamma 1$ (Fe2Zn21, fcc, brittle, very hard), and $\delta$ (FeZn7, hcp, ductile, hard), which consists of different intermetallic phases which are formed during hot-dip galvanizing. Coating adhesion is influenced by ruggedness of the coating/steel interface; that is, formation of discontinuous $\Gamma$ phase contributes to increasing the adhesion strength [15-17]. 


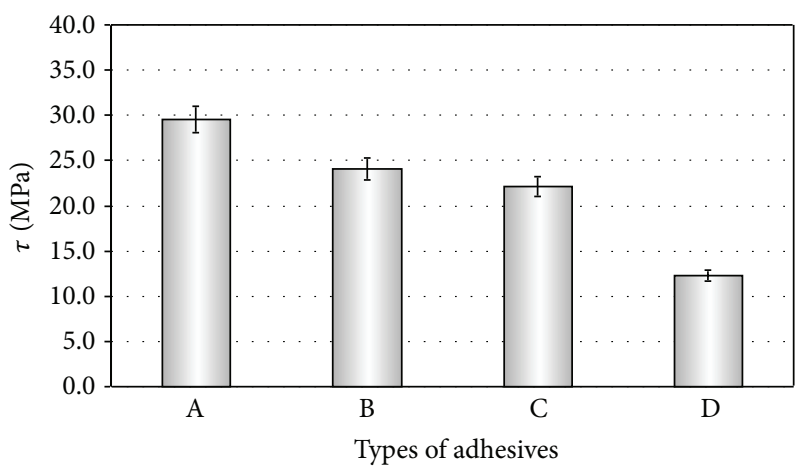

FIGURE 5: The final values of the shear strength under tension.

The average shear strength with standard deviation for applied adhesives is as follows: adhesive $\mathrm{A} \tau_{\mathrm{A}}=29.5 \pm$ $0.3 \mathrm{MPa}$, adhesive $\mathrm{B} \tau_{\mathrm{B}}=24.1 \pm 2.9 \mathrm{MPa}$, adhesive $\mathrm{C} \tau_{\mathrm{C}}=$ $22.1 \pm 0.4 \mathrm{MPa}$, and adhesive $\mathrm{D} \tau_{\mathrm{D}}=12.3 \pm 0.6 \mathrm{MPa}$. The highest average value of shear strength was obtained for adhesive A: $\tau_{\mathrm{A}}=(29.5 \pm 0.3) \mathrm{MPa}$ (Figure 5).

The success of the single lap shear tensile test relies on the strength and adhesion of the adhesive, which must be superior to that of the zinc coatings [10].

The fractures of bonded joints from both sides after shear strength lap destruction by tensile loading were evaluated. As shown in Figure 6(a) the adhesive covered on the overlap region of zinc coated samples indicated a cohesive-adhesive failure mode; that is, the adhesive ruptured within itself (cohesive failure) and also on the same places was separated from one of the substrates (adhesive failure). In Figure 6(b) the adhesive indicated a cohesive-adhesive failure mode. These results correlate with formation of suitable interface, the zinc coating/steel interface, that is, formation of phases which contributes to required adhesion strength (Figure 4).

Adhesion performance was additionally determined by a peel test (EN ISO 11339:2010). Based on the test results of shear strength under tension the adhesive type A was selected for T-peel test due to its highest strength. Under the terms of this test the material with a thickness of $0.55 \mathrm{~mm}$ was requested. The maximum value of peel strength $\sigma_{P S}=$ $1.14 \mathrm{~N} / \mathrm{mm}$ was obtained when 10 samples were tested. The results show that adhesion of zinc coating to substrate is higher compared with strength of adhesive A (Figure 7).

Besides the evaluation of mechanical properties of bonded joints also the assessment of bonded joint fracture type according to ISO 10365 is required.

All tested adhesives under experimental work of the shear strength deformed the joint surface. Based on test results it can be stated that the adhesive strength of all applied adhesives is sufficient.

Original morphology of zinc surface (Figure 8(a)) was after the shear strength test under tension greatly deformed due to the adhesion of the A adhesive (Figure 8(b)).

The results show that adhesion of zinc layer to substrate is high, the continuity of zinc layer was not destroyed, and

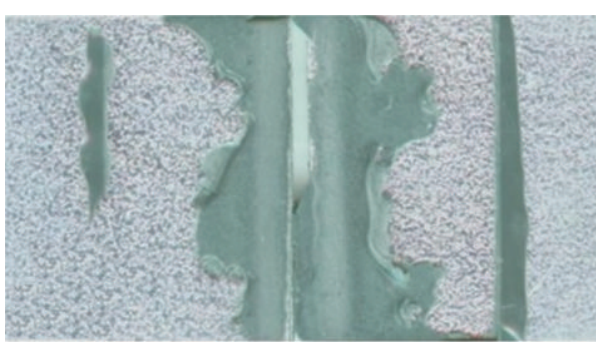

(a)

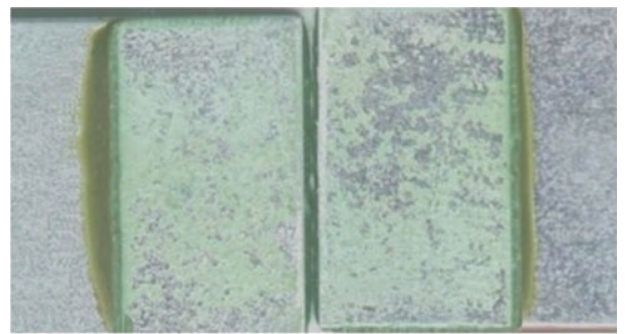

(b)

FIGURE 6: Fracture surfaces of bonded joints for adhesive (a) type A and (b) type B.

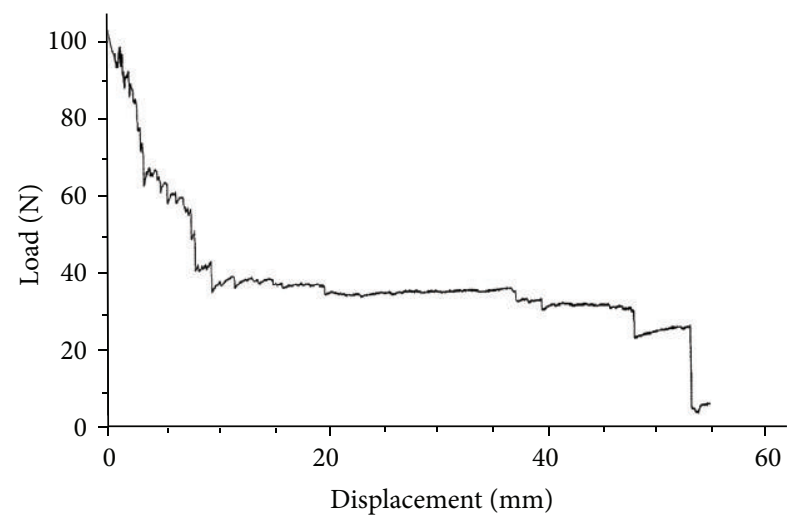

FIgURE 7: Typical force-displacement curve for a T-peel test for adhesive A.

fracture area is visibly deformed (Figure 8) in the direction of load of bonded joints. EDX analysis (Figure 9) confirmed obtained results on adhesion of zinc coating to the substrate.

Specimens with dimensions of $300 \mathrm{~mm} \times 1500 \mathrm{~mm} \times$ $1.75 \mathrm{~mm}$ were tested in-service under similar conditions to the T-peel test (critical load) with the aim to obtain information on adhesive behaviour on large surfaces (Figures 10(a) and 10(b)). The adhesive indicated a cohesive failure mode; zinc coating shows good adhesion.

It is necessary to take into account that bonded joint quality to a great extent depends on many factors like, for example, amount and type of used lubricant, type of used substrate, and its surface morphology or surface treatment. Such huge amount of variable parameters makes problems about testing bonded joint quality quite difficult and requires further deepening of knowledge about individual parameters influence. 


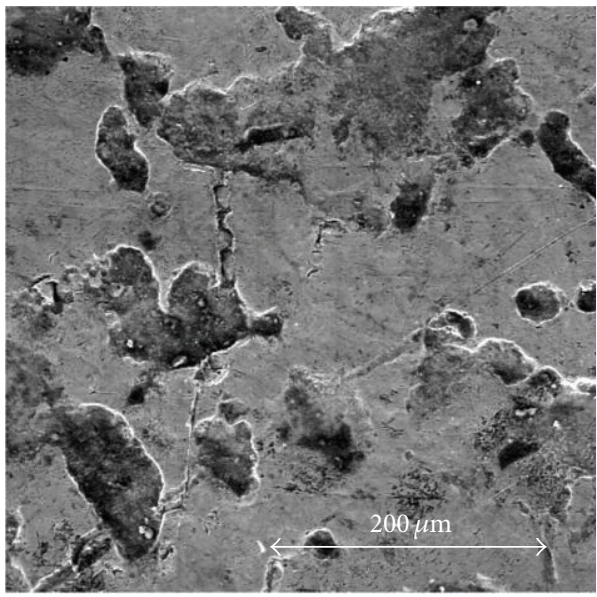

(a)

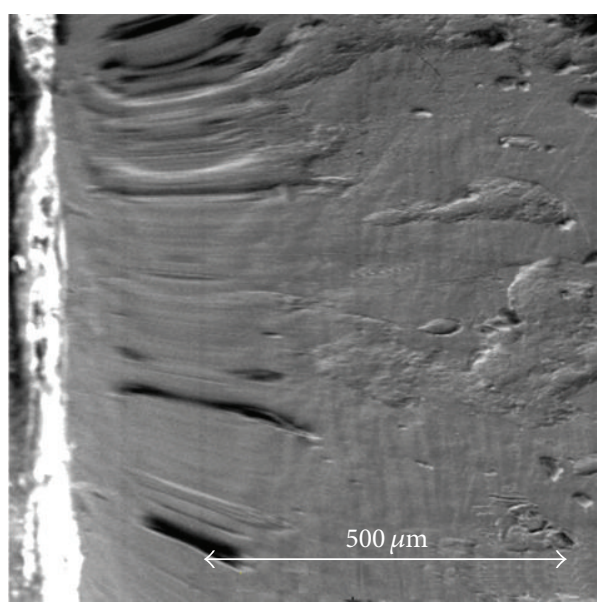

(b)

FIGURE 8: (a) Original morphology of zinc surface; (b) deformed Zn coating in the direction of tensile force after lap shear test (adhesive A).

SE, 9493051

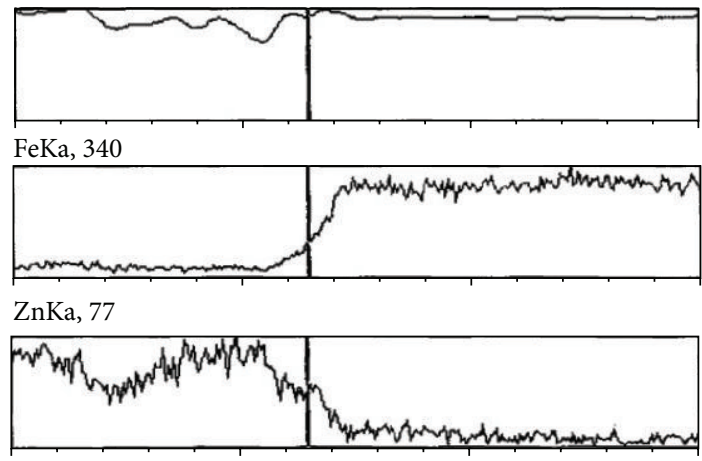

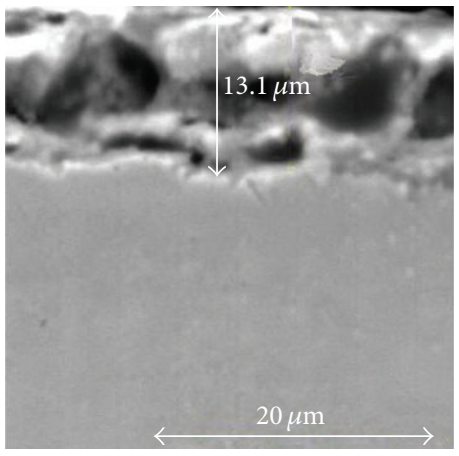

FIGURE 9: EDX analysis and cross section of $\mathrm{Zn}$ coating after shear strength under tension.

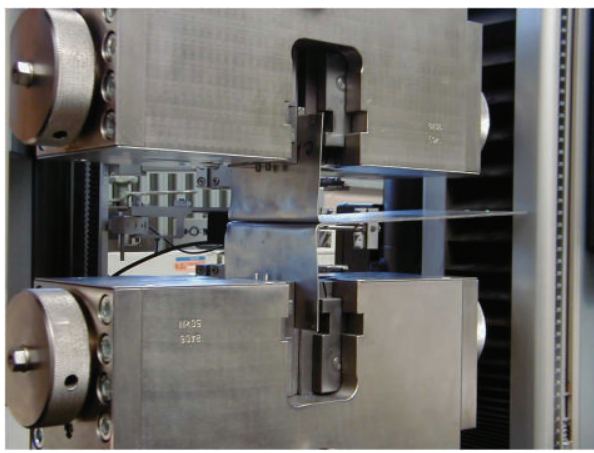

(a)

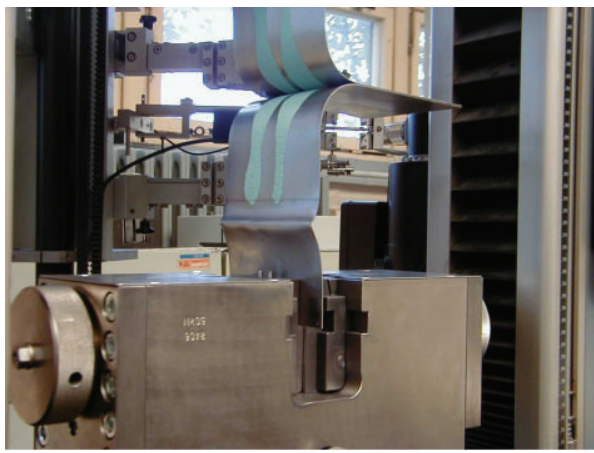

(b)

FIGURE 10: View on peel test of bonded joints (a) before peeling and (b) during peeling.

\section{Conclusion}

The performance of hot-dip galvanized zinc coated steel sheets is associated with properties of the zinc coatings on steel substrates and properties of the coatings/steel interfaces. A great number of studies were carried out to investigate the failure behaviour of adhesively bonded joints with zinc coated steel substrates. To clarify the mechanism of adhesion on a microstructural level, standard tests are employed to evaluate adhesion behaviour; these methods usually provide qualitative results.

The study was oriented to the possibility of quantification of adhesion of zinc coating to the steel substrate. Bonded joints were selected as one of the options to evaluate adhesion 
of the zinc coating to steel substrate by the bonding strength applying the shear strength and T-peel tests.

Based on experimental tests we may state the following:

(1) Quantitative analysis of adhesion of zinc to steel shows that its value is higher than shear strength at tensile loading 36-41 MPa, adhesive A.

(2) The shear strength in tension for adhesive A was obtained $\tau_{\mathrm{A}}=29.5 \pm 0.3 \mathrm{MPa}$ without failure of the zinc coating/substrate interface.

(3) Critical load case-T-peel test-confirmed obtained references about required adhesion of the zinc layer to the substrate material (see point (1)). The value of peel strength for adhesive A was $\sigma_{P S}=1.14 \mathrm{~N} / \mathrm{mm}$.

\section{Competing Interests}

The authors declare that there is no conflict of interests regarding the publication of this paper.

\section{Acknowledgments}

The authors gratefully acknowledge the support of the Slovak Grant Agency VEGA, Grant no. 1/0117/15 and VEGA Grant no. $1 / 0425 / 14$. The authors express their thanks to the firm La Composite Letov for cooperation at preparation of adhesive joints.

\section{References}

[1] A. R. Marder, "The metallurgy of zinc-coated steel," Progress in Materials Science, vol. 45, no. 2, pp. 191-271, 2000.

[2] C. E. Jordan, K. M. Goggins, and A. R. Marder, "Interfacial layer development in hot-dip galvanneal coatings on interstitial free (IF) steel," Metallurgical and Materials Transactions A, vol. 25, no. 10, pp. 2101-2109, 1994.

[3] G. M. Song, T. Vystavel, N. van der Pers, J. T. M. de Hosson, and W. G. Sloof, "Relation between microstructure and adhesion of hot dip galvanized zinc coatings on dual phase steel," Acta Materialia, vol. 60, no. 6-7, pp. 2973-2981, 2012.

[4] A. Baldan, "Adhesion phenomena in bonded joints," International Journal of Adhesion and Adhesives, vol. 38, pp. 95-116, 2012.

[5] L. Chen, R. Fourmentin, and J. R. McDermid, "Morphology and kinetics of interfacial layer formation during continuous hotdip galvanizing and galvannealing," Metallurgical and Materials Transactions A, vol. 39, no. 9, pp. 2128-2142, 2008.

[6] G.-M. Song and W. G. Sloof, "Effect of alloying element segregation on the work of adhesion of metallic coating on metallic substrate," Surface and Coatings Technology, vol. 205, no. 19, pp. 4632-4639, 2011.

[7] P. N. B. Reis, J. A. M. Ferreira, and F. Antunes, "Effect of adherends rigidity on the shear strength of single lap adhesive joints," International Journal of Adhesion \& Adhesives, vol. 31, no. 4, pp. 193-201, 2011.

[8] A. Gallego, J. F. Gil, J. M. Vico, J. E. Ruzzante, and R. Piotrkowski, "Coating adherence in galvanized steel assessed by acoustic emission wavelet analysis," Scripta Materialia, vol. 52, no. 10, pp. 1069-1074, 2005.
[9] G.-M. Song and W. G. Sloof, "Characterization of the failure behavior of zinc coating on dual phase steel under tensile deformation," Materials Science and Engineering A, vol. 528, no. 21, pp. 6432-6437, 2011

[10] M. Davis and D. Bond, "Principles and practices of adhesive bonded structural joints and repairs," International Journal of Adhesion and Adhesives, vol. 19, no. 2-3, pp. 91-105, 1999.

[11] ISO, "Adhesives. Designation of main failure patterns," ČSN ISO 10365:1995, 1995.

[12] Ç. Özes and N. Neşer, "Experimental study on steel to FRP bonded lap joints in marine applications," Advances in Materials Science and Engineering, vol. 2015, Article ID 164208, 6 pages, 2015.

[13] ASTM Standards, "Standard test method for apparent shear strength of single-lap-joint adhesively bonded metal specimens by tension loading (metal-to-metal)," ASTM D 1002-10, 2010.

[14] ISO, "Adhesives: T-peel test for flexible-to-flexible bonded assemblies," EN ISO 11339:2010, 2010.

[15] M. Kollárová, Štruktúra a vlastnosti zinkových vrstiev na oceliach pre automobilový priemysel [Dissertation Thesis], Ústav Materiálového Výskumu SAV, Košice, Slovakia, 2005 (Slovak).

[16] A. Leško, M. Kollárová, and L. Parilák, "Deformation and fracture of hip dip galvanized steel sheet," Metallic Materials, vol. 40, no. 1, pp. 1-10, 2002.

[17] M. Kollárová, M. Džupon, A. Leško, and L. Parilák, "Formation of outburst structure in hot dip galvannealed coatings on IF steels," Metalurgija, vol. 46, no. 1, pp. 9-14, 2007. 

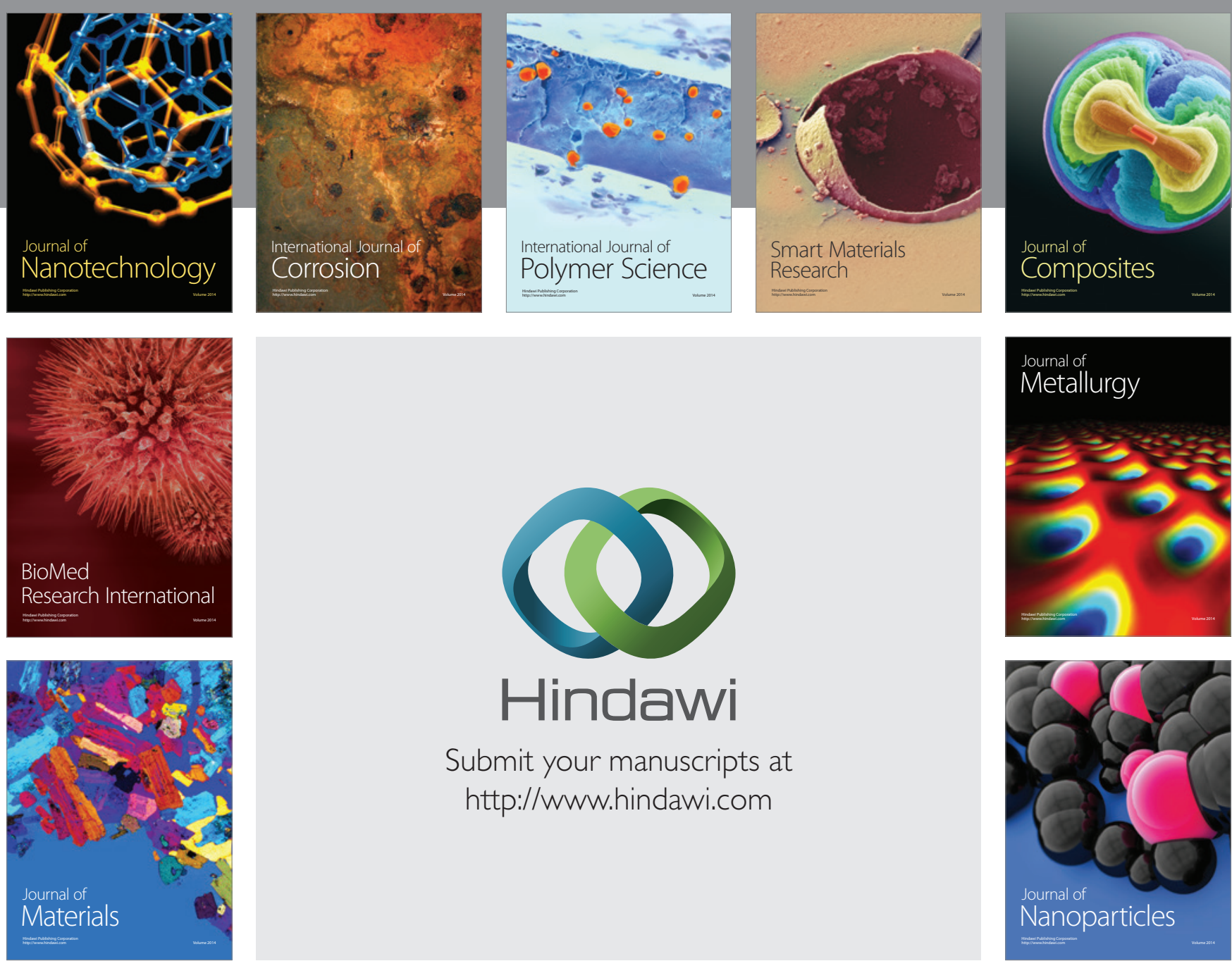

\section{Hindawi}

Submit your manuscripts at

http://www.hindawi.com

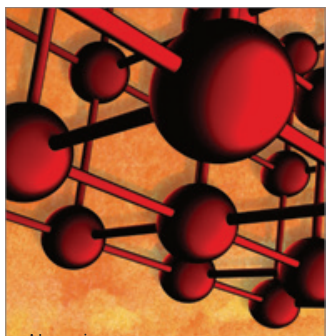

Materials Science and Engineering
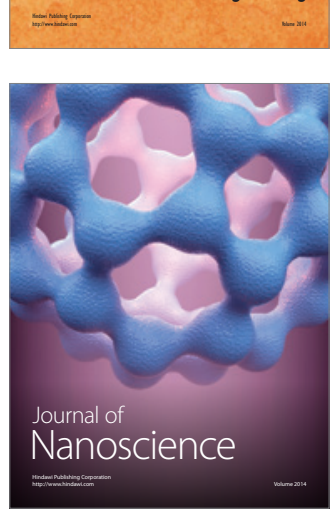
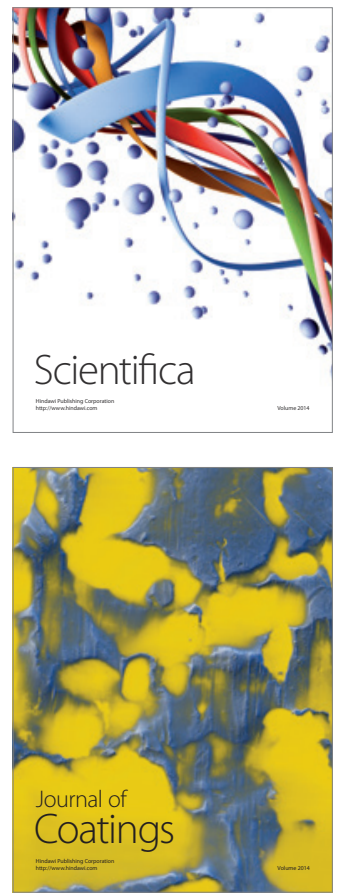
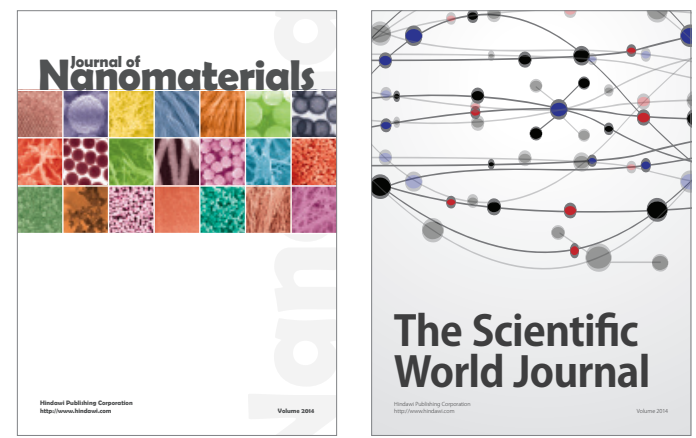

The Scientific World Journal
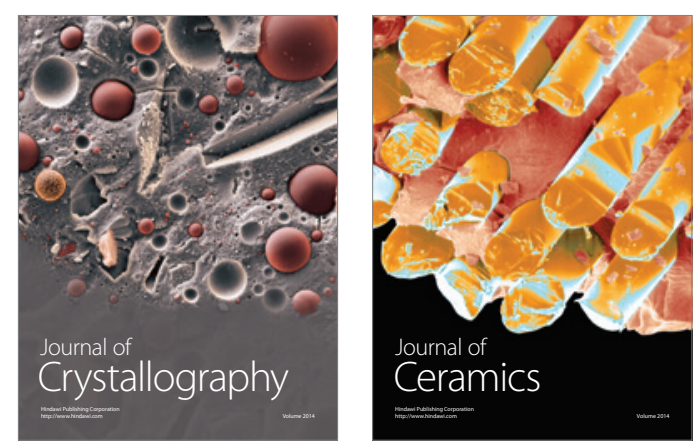
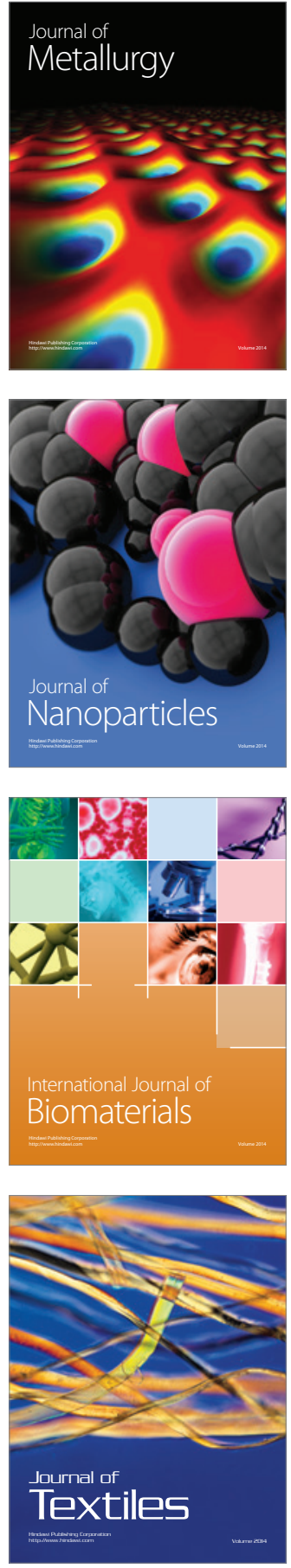